\title{
GCU
}

Glasgow Caledonian

University

University for the Common Good

\section{Comparative analysis of the toxicity of gold nanoparticles in zebrafish}

Patibandla, Srinath; Zhang, Yinan; Tohari, Ali Mohammad; Gu, Peng; Reilly, James; Chen, Yu; Shu, Xinhua

Published in:

Journal of Applied Toxicology

DOI:

10.1002/jat.3628

Publication date:

2018

Document Version

Author accepted manuscript

Link to publication in ResearchOnline

Citation for published version (Harvard):

Patibandla, S, Zhang, Y, Tohari, AM, Gu, P, Reilly, J, Chen, Y \& Shu, X 2018, 'Comparative analysis of the toxicity of gold nanoparticles in zebrafish', Journal of Applied Toxicology, vol. 38, no. 8, pp. 1153-1161.

https://doi.org/10.1002/jat.3628

\section{General rights}

Copyright and moral rights for the publications made accessible in the public portal are retained by the authors and/or other copyright owners and it is a condition of accessing publications that users recognise and abide by the legal requirements associated with these rights.

Take down policy

If you believe that this document breaches copyright please view our takedown policy at https://edshare.gcu.ac.uk/id/eprint/5179 for details of how to contact us. 


\section{Comparative analysis of the toxicity of gold nanoparticles}

3 Srinath Patibandla ${ }^{1}$, Yinan Zhang ${ }^{2,3}$, Ali Mohammad Tohari ${ }^{1,4}$, Peng $\mathrm{Gu}^{2}$, James Reilly ${ }^{1}$, Yu

4 Chen $^{2}$, Xinhua Shu ${ }^{1 *}$

51 Department of Life Sciences, Glasgow Caledonian University, Glasgow G4 0BA

62 Department of Physics, University of Strathclyde, Glasgow G4 0NG

7 3. College of Physics, Jilin University, Changchun, 130012, China

84 King Fahad Hospital, Jazan, Saudi Arabia P.O BOX 204

$9 \quad *$ Corresponding author Xinhua Shu, Email: Xinhua.Shu@gcu.ac.uk

10

11

12 


\section{Abstract}

The use of nanoparticles - particles that range in size from 1 to 100 nanometres - has become increasingly prevalent in recent years, bringing with it a variety of potential toxic effects. Zebrafish embryos were exposed during the 3-day post-fertilisation period to gold nanospheres (GSSs), gold nanorods (GNRs), gold nanorods coated with polystyrene-sulfate (PSS-GNRs), and gold nanorods coated with both polystyrene-sulfate and polyallamine hydrochloride (PAH/PSS-GNRs). All nanorods were stabilised with cetyltrimethylammonium bromide (CTAB). GNSs were the least toxic of the nanoparticles studied, with exposure resulting in no significant changes in mortality, hatching or heart rate. Exposure to GNRs and PSS-GNRs resulted in significant increases in mortality and significant decreases in hatching and heart rate. Treatment with GNRs caused significant changes in the expression of a variety of oxidative stress genes. The toxic effects of GNRs were ameliorated by coating them with polystyrene-sulfate and, to a more marked extent, with a double coating of polystyrene-sulfate and polyallamine hydrochloride.

Keywords Nanoparticles; nanospheres; nanorods; zebrafish; toxicity

\section{Short abstract}

Zebrafish embryos were exposed during the 3-day post-fertilisation period to gold nanospheres (GSSs), gold nanorods (GNRs), and to gold nanorods coated with polystyrenesulfate alone (PSS-GNRs) or in combination with polyallamine hydrochloride (PAH/PSSGNRs). All nanorods were stabilised with cetyltrimethylammonium bromide. Exposure to GNSs had no significant effects, whereas exposure to GNRs and PSS-GNRs significantly affected hatching, heart rate and mortality. Exposure to GNRs caused significant changes in the expression of various oxidative stress genes. Coated nanorods had markedly less toxic effects. 
Particles ranging in size from 1 to 100 nanometres (nm) are known as nanoparticles; the use of such particles is known as nanotechnology. In the field of biology, engineered nanoparticles have been put to a variety of uses, including (to mention only a few examples): as fluorescent biological labels, in the diagnosis, monitoring and destruction of tumours, in detection of pathogens and proteins, in gene expression and phagokinetic studies, and in MRI contrast enhancement (Salata, 2004; Zhang et al, 2010, 2011, 2015;). Carbon nanoparticles are widely used in vehicles and sports equipment. Cerium oxide is used in electronics, fuel additives and biomedical supplies, while titanium dioxide is widely employed in cosmetics, paints and coatings. Silver nanoparticles are used in the food and textile industries for their antimicrobial properties, while iron nanoparticles are used as smart fluids in the fields of optics and food supplement industries Gold nanoparticles have been used in drug delivery, tumour detection, gene therapy, and as photothermal agents (Asharani et al., 2008; Wei, 2015, 2016). variety of in-vitro and in-vivo studies. There is evidence that nanoparticles such as carbon, blood-brain barrier, neuronal damage and cerebral oedema after exposure to nanoparticles (Cattaneo et al., 2014). Zinc oxide nanoparticles show anti-microbial activity by damaging cell membranes and organelles and might cause the same kind of damage to eukaryotic cells (Marambio-Jones et al., 2010). Zinc oxide nanoparticles can cause cytotoxicity in immune 
nanoparticles have a greater potential for damage compared to larger particles (Asharani et al., 2008). Given the range of possible toxic effects, and the wide variety of nanoparticles implicated in these effects, more research is needed to identify the ways by which they disperse, their impact on organisms and on the environment, and how to minimise these effects.

One approach is to use the zebrafish animal model to assess toxicity caused by nanoparticles. The zebrafish is recognised as an alternative model by which to analyse human physiology, development and disease. It has been used widely because of its many benefits such as easy maintenance in labs, production of large number of optically transparent eggs, homology to the human genome, and rapid development of the embryo to adult fish by the end of week 1 post fertilisation. The zebrafish embryos are preferable because of their sensitivity to test chemicals and their ability to absorb test substances through their skin and gills from the surrounding water (Bar-Ilan et al., 2009). Transmission electron microscopy (TEM) and acridine orange staining have been used to investigate the distribution of nanoparticles (and the resulting cell death) in blood, brain and yolk sac in zebrafish embryos (Asharani et al., 2008;).

\section{MATERIALS AND METHODS}

\subsection{Nanoparticle syntheses and characterization}

Gold nanospheres (GNSs) were prepared according to the Turkevich method (Kimling et al. 2006). Gold nanorods (GNRs) were synthesised by the seeded growth method (Murphy \& Jana (2002). Typically, 2.5ml $\mathrm{HAuCl}_{4} \times 3 \mathrm{H}_{2} \mathrm{O}(0.001 \mathrm{M})$ and $0.6 \mathrm{ml}$ ice-cold $\mathrm{NaBH}_{4}(0.01 \mathrm{M})$ were added to $7.5 \mathrm{ml}$ cetyltrimethylammonium bromide (CTAB) $(0.12 \mathrm{M})$ to prepare the seed solution. The growth solution was synthesized by adding $0.15 \mathrm{M}$ benzyldimethylhexadecylammonium chloride (BDAC), 50ml $\mathrm{HAuCl}_{4} \mathrm{x} 3 \mathrm{H}_{2} \mathrm{O}(0.001 \mathrm{M}), 3 \mathrm{ml}$ 
silver nitrate $\left(\mathrm{AgNO}_{3}\right)(0.004 \mathrm{M})$ and $700 \mu \mathrm{l}$ ascorbic acid $(0.778 \mathrm{M})$ to $50 \mathrm{ml}$ CTAB solution (0.1M). $80 \mu \mathrm{l}$ seed solution ( 2 hours after preparation) was then injected into the growth solution to grow gold nanorods. The nanorods could then be coated with a single layer of PSS or a double layer of PAH-PSS using the method described by Omura et al. (2009).

GNSs, GNRs and polymer coated GNRs sample solutions (quantity 3ml) were placed in a quartz cuvette and absorption spectroscopy studies carried out using a JASCO V-660 absorption spectrometer. The physical properties of the prepared gold nanoparticles were characterized using transmission electron microscopy (TEM).

\subsection{Nanoparticle treatment}

The zebrafish (Danio rerio) used in this study were obtained from our fish breeding stocks ZEBTEC zebrafish housing system (Tecniplast), Glasgow Caledonian University. Fish are kept in 5L plastic tanks supplied with a constant flow of conditioned water at a temperature of $28^{\circ} \mathrm{C}$ with $\mathrm{pH} 7.5$ on a $14: 10 \mathrm{~h}$ light/dark photoperiod. Eggs were collected from a group of spawned zebrafish.

The embryos were exposed to GNSs, GNRs, PSS-GNRs or PAH/PSS-GNRs at concentrations of $0.01,0.025,0.05$ and $0.1 \mathrm{nM}$ in a 48 -well plate. To prepare the dilutions, each sample of nanoparticles was mixed with system water. For the negative control, system water alone was used. The collected eggs were bleached with chlorine water at a concentration of $5 \mu \mathrm{l}$ of $10-15 \%$ chlorine water in $17 \mathrm{ml}$ of system water for 2 to 3 minutes to avoid any contamination and infection, then washed three times with fresh system water to remove any traces of chlorine. Within $2 \mathrm{~h}$ post fertilisation (hpf), fertilised and normally developing fish eggs were transferred into each well (8 embryos/well) using a plastic pipette, then incubated at $28^{\circ} \mathrm{C}$. The eggs were exposed to the test samples during the 3-days postfertilisation period and inspected at 24, 48 and 72 hpf for mortality, hatching, morphological abnormalities, heart rate, body length and eye size. 
Mortality of the embryos was noted at 24, 48 and 72 hours of nanoparticle treatment. The opaque and white embryos were transferred along with the medium to other empty wells and inspected in order to differentiate dead embryos (which quickly degrade) from abnormal or malformed embryos. The abnormal embryos were again transferred to their respective test wells. Mortality rate is expressed as the percentage of dead embryos after 72 hpf (hours post fertilisation). Hatching rate (expressed as the percentage of embryos that had hatched by 72 hpf) was recorded. Heart rate was monitored at $72 \mathrm{hpf}$ using a stopwatch and direct microscopic observation. Tail detachment, the formation of somites, presence of brown flakes and any abnormalities were observed and noted.

\subsection{Acridine orange staining}

To investigate the cell death (apoptosis) caused by nanoparticles, acridine orange staining of nanoparticle-treated embryos was performed. Acridine orange is a nucleic-acid-selective metachromatic dye that emits green fluorescence upon intercalation with DNA and is widely used for detecting the sites of apoptosis in zebrafish. Acridine orange can permeate apoptotic cells and bind to DNA whereas normal healthy cells are non-permeable to acridine orange. Acridine orange staining was performed according to previous description (Shu et al., 2010). Briefly, the embryos were transferred to $1.5 \mathrm{ml}$ Eppendorf tubes and stained with acridine orange $(5 \mu \mathrm{g} / \mathrm{ml})$ for $20 \mathrm{~min}$ at room temperature. Embryos were washed quickly in $1 \times \mathrm{PBS}$ and were observed using green fluorescence microscopy. The fluorescent signals from apoptotic cells (heart and eye areas) were quantified using ImageJ software (https://imagej.nih.gov/ij/). In brief, the heart and eye areas were selected using the selection tool, and the integrated density and mean gray value were measured. In each case, a nearby region with background fluorescence was selected for comparison, and the integrated density and mean gray value were measured for this region. Total fluorescent signals were calculated 
using the formula: total fluorescent signals = integrated density - mean fluorescent signals of background.

\subsection{RNA extraction}

Zebrafish eggs were collected in a Petri dish and bleached with chlorine to prevent infections. At 6hpf embryos were treated with 4 nanoparticle samples (2.5 $\mu \mathrm{M}$ GNS, $0.01 \mathrm{nM}$ GNR, $0.025 \mathrm{nM}$ PSS-GNR and $0.05 \mathrm{nM}$ PAH/PSS-GNR) till 72hpf with E3 medium as control. The treated zebrafish embryos were homogenised in $1 \mathrm{ml}$ of TRIzol ${ }^{\circledR}$ Reagent (Invitrogen cat. no. 15596-026) per 50-100 mg of the tissue sample. Homogenised samples were incubated for 5 minutes at room temperature to allow complete dissociation of the nucleoprotein complex. $200 \mu \mathrm{l}$ of $100 \%$ chloroform per $1 \mathrm{ml}$ of TRIzol® Reagent used for homogenization was added to each sample. All samples were manually and vigorously shaken for 15 seconds and allowed to stand for 2-3 minutes at room temperature. All tubes were centrifuged at $12,000 \times g$ for 15 minutes at $4^{\circ} \mathrm{C}$. The resulted supernatant contains three aqueous layers in which RNA is found in the top layer. Each upper aqueous layer was transferred to a fresh $1.5 \mathrm{ml}$ Eppendorf tube and $500 \mu \mathrm{l}$ of $100 \%$ isopropanol per $1 \mathrm{~mL}$ of TRIzol ${ }^{\circledR}$ Reagent used for homogenization was added to the aqueous phase and allowed to stand for 10 minutes at room temperature. All tubes were then centrifuged at $12,000 \times g$ for 10 minutes at $4^{\circ} \mathrm{C}$. Supernatants were discarded by inverting the tubes leaving only the RNA pellet which was then washed by adding $75 \%$ ethanol. Following centrifugation the RNA pellet was allowed to stand for 5-10 minutes at room temperature to permit the evaporation of remaining traces of the ethanol wash. The RNA pellet was resuspended in $25 \mu \mathrm{l}$ of RNasefree water and the purity was assessed using Nanodrop spectrophotometer (ND1000) in which RNA purity is defined as A260/280 ratio. 
173 Complementary DNA (cDNA) synthesis was performed using Roche Transcriptor High

174 Fidelity cDNA Synthesis Kit (cat. no. 05091284001) according to the manufacturer's

175 instructions. The protocol was carried out in $20 \mu \mathrm{l}$ reaction volume in two steps. First step:

$1764 \mu \mathrm{l}$ of neat RNA was incubated with $2 \mu \mathrm{l}$ of $600 \mu \mathrm{M}$ random hexamer primer and $5.4 \mu \mathrm{l}$

177 RNase-free water for 10 minutes at $65^{\circ} \mathrm{C}$ and the product was immediately chilled in ice. The

178 second step involved addition of $8.6 \mu \mathrm{l}$ of a master mix containing $4 \mu \mathrm{l}$ of $5 \mathrm{X}$ transcriptor

179 high fidelity reverse transcriptase reaction buffer, $0.5 \mu \mathrm{l}$ of $40 \mathrm{U} / \mu$ l Protector RNase inhibitor,

$1802 \mu \mathrm{l}$ of $10 \mathrm{mM}$ deoxynucleotide mix, $1 \mu \mathrm{l}$ of $0.1 \mathrm{M}$ Dithiothreitol (DTT) and $1.1 \mu \mathrm{l}$ of 100U/

$181 \mu \mathrm{l}$ of transcriptor high fidelity reverse transcriptase followed by brief centrifugation at $4^{\circ} \mathrm{C}$.

182 The cDNA reaction mixture was incubated in a thermal cycler for 10 minutes at $29^{\circ} \mathrm{C}$

183 followed by a second incubation for 60 minutes at $48^{\circ} \mathrm{C}$ and then final incubation for 5

184 minutes at $85^{\circ} \mathrm{C}$ to inactivate the transcriptor high fidelity reverse transcriptase. The resultant

185 cDNA was then quantified using Nanodrop spectrophotometer (ND1000) and stored at $18620^{\circ} \mathrm{C}$

187 2.6 Quantitative real-time PCR (qRT-PCR)

188 The expression of candidate oxidative stress genes following zebrafish microparticles treatment was analysed using Platinum ${ }^{\circledR}$ SYBR ${ }^{\circledR}$ Green qPCR SuperMix-UDG master mix (Invitrogen Cat 11733-046) according to the manufacturer's protocol in a final volume of $20 \mu \mathrm{l}$ containing $10 \mu \mathrm{l}$ of Platinum ${ }^{\circledR}$ SYBR ${ }^{\circledR}$ Green qPCR mix, $7 \mu \mathrm{l}$ of PCR-grade water, $1 \mu \mathrm{l}$ of forward primer $(10 \mu \mathrm{M}), 1 \mu \mathrm{l}$ of reverse primer $(10 \mu \mathrm{M})$, and $1 \mu \mathrm{l}$ of $50 \mathrm{ng} / \mu \mathrm{l}$ of cDNA. The primer sequences of target genes are listed in Table 1. The qRT-PCR reaction mixture was 194 then assayed using the Biorad CFX96 ${ }^{\mathrm{TM}}$ Real-Time PCR detection system under the following PCR conditions: UDG incubation at $50^{\circ} \mathrm{C}$ for 2 minutes followed by Taq polymerase activation for at $95^{\circ} \mathrm{C}$ for 2 minutes and 40 cycles of $95^{\circ} \mathrm{C}$ for 15 seconds, $55^{\circ} \mathrm{C}$ 197 for 30 seconds, and $72^{\circ} \mathrm{C}$ for 1 minute. Fluorescence signal detection was measured at $72^{\circ} \mathrm{C}$. 
The amount of mRNA is determined by normalizing the threshold cycle $C_{\mathrm{T}}$ of the candidate gene to the $C_{\mathrm{T}}$ of ZF18sRNA reference gene in the same sample based on the following formula: the average $C_{\mathrm{T}}$ of target gene - the average $C_{\mathrm{T}}$ of reference gene in which this result is recognized as $\Delta C_{\mathrm{T}}$ where it is specific for each gene and can be compared with $\Delta C_{\mathrm{T}}$ of calibration samples. The difference between $\Delta C_{\mathrm{T}}$ of target and control genes is known as $\Delta \Delta C_{\mathrm{T}}$. The relative quantification of target gene expression is calculated in comparison with control according to the following formula: $2^{-\Delta \Delta C T}$ and represented as a fold change.

\subsection{Statistical analysis}

All experiments were done at least in triplicate. Data were expressed as mean $( \pm$ standard error) and subjected to analysis of variance (ANOVA) followed by the Tukey's test. ANOVA assumptions (normality and homogeneity of variances) were previously checked. The significance level adopted was 95\% (C=0.05).

\section{RESULTS}

\subsection{Characteristics of nanoparticles}

The absorption spectra for GNRs, PSS-GNRs and GNSs are shown in Figure 1. As can be seen, the surface plasmon of GNSs peaks at 525nm, while there are two peaks both for GNSs and PSS-coated GNRs: one located around 525nm (which is referred to as the transverse mode) and one in the near infra-red band (known as the longitudinal mode). The surface plasmon structure depends critically on the particle size, shape and surface conditions. Figure 2 shows typical TEM images of gold nanospheres and gold nanorods of longitudinal surface plasmon resonance peak centred at around $800 \mathrm{~nm}$. Diameter $38.1 \pm 2.8 \mathrm{~nm}$ are derived from TEM analysis for gold nanospheres. Diameter $12.7 \pm 1.8 \mathrm{~nm}$ and length $51.6 \pm 8.2 \mathrm{~nm}$ are found for gold nanorods. The aspect ratio (long axis divided by diameter) of GNRs is around 4. Further PSS and PAH coating were applied to this GNR.

\subsection{Effect of nanoparticles on mortality, hatching and heart rate}


223 To assess the potential toxicity of the nanoparticles, testing was performed in zebrafish embryos at 6hpf to 120hpf. Toxic endpoints such as mortality, hatching, heart rate and abnormalities were observed and recorded. The doses $(0.01 \mathrm{nM}, 0.025 \mathrm{nM}, 0.05 \mathrm{nM}$ and $0.1 \mathrm{nM}$ ) of nanoparticles were prepared from $0.1 \mathrm{nM}$ stock. The toxic end points were observed, recorded and analysed.

Mortality was defined as the percentage of dead zebrafish eggs from the total number of eggs used for the particular test sample. In the control groups at 72 hpf mortality was below $10 \%$ in all experiments, therefore the requirement of OECD guidelines (http://www.oecd.org/) for a valid test was always met and the observed effects can be attributed to these nanoparticle samples. Most of the eggs showed coagulation at 24hpf and by 48hpf many of the vital embryos had no heartbeat and were determined as mortal. A few showed developmental retardation and were determined as mortal at 24hpf. Mortality rate is shown in Figure 3. GNRs (CTAB capped) induced a statistically significant increase in mortality at all doses. PSS-GNRs induced a statistically significant increase in mortality only at the high doses. PAH/PSS-GNRs and GNSs caused no significant mortality at all doses tested.

Hatching is defined as the percentage of embryos hatched by the end of the $3^{\text {rd }}$ day from the total number of embryos used for the particular test sample. In the control groups at 72 hpf, the hatching was above $70 \%$ in all experiments. Embryos out of their chorion were determined as hatched and the others were termed as unhatched. Hatching rate is shown in Figure 4. Exposure to GNRs and PSS-GNRs caused a statistically significant decrease in hatching at all doses. PAH/PSS-GNRs induced a statistically significant decrease in hatching only at high doses and GNSs had no effect on hatching at all the doses tested.

Heart rate (number of heart-beat per minute) at the end of treatment was observed with a microscope and counted using a cell counter. The heart rate of the nanoparticle-treated 
samples was compared with the heart rate of control embryos (E3 medium) at 120hpf. Heart rates are shown in Fig. 5. GNRs and PSS-GNRs induced a statistically significant decrease in the heart rate in zebrafish embryos at the high doses only. PAH/PSS-GNRs and GNSs showed no significant impact on the heart rate at all doses tested.

\subsection{Effect of nanoparticles on expression of oxidative stress genes}

253 Oxidative stress represents an imbalance between the production of reactive oxygen species 254 (ROS) and the neutralization of excess ROS by cellular antioxidant defences. Nanoparticles have been demonstrated to cause oxidative stress in different types of cells and animal models including zebrafish (Abdal Dayem et al., 2017; Choi et al., 2010; Faria et al., 2014; Zhao et al., 2016). Using qRT-PCR we examined expression of oxidative stress related genes in nanoparticle treated and control zebrafish embryos and found that treatment with GNRs induced significant changes in the expression of all the oxidative stress related genes studied compared to the controls (Fig. 6). PAH-PSS-GNRs induced a significant change only in catalase expression, while treatment with GNSs and PSS-GNRs caused no significant change in the examined genes. The results clearly demonstrate that PSS coating on GNR nanoparticles reduced toxicity, possibly by forming a protective layer around CTAB of GNRs.

\subsection{Effect of nanoparticles on apoptosis}

Acridine orange staining was performed to detect any apoptosis caused by the nanoparticle treatment (Fig. 7). It is important for a multicellular organism to maintain and regulate cell numbers. One such response to injury or infection is apoptosis. Acridine orange staining works on the principle that healthy cells are not permeable to acridine orange, which can pass through only the damaged cell membrane. Each bright spot represents an area of cell death, with the intensity of fluorescence directly correlated to the extent of apoptosis (Fig. 7A-E). 
272 Apoptosis was seen in all the cases of nanoparticle treatment, although the intensity varied,

273 becoming greater with a rise in nanoparticle concentration (data not shown).

\section{DISCUSSION}

275

From the displayed results (Fig. 3, 4, and 5), it can be seen that GNRs (CTAB capped) showed high toxicity when compared to the other types of gold nanoparticles tested. GNRs induced a statistically significant increase in mortality and decrease in hatching percentage at all doses. GNRs also showed a significant decrease in heart rate at high doses. PSS-GNRs induced a statistically significant decrease in hatching rate at all doses and increased mortality and decreased heart rate at high doses. PAH/PSS-GNRs showed a significant decrease in hatching at high doses. GNSs showed no significant toxicity even at the highest dose. This may be due to the shape of the nanoparticle or the surfactant used for the purpose of capping. It is clearly seen that PSS and PAH/PSS-capped GNRs induced less toxic effects when compared to GNRs. The toxic impact of GNRs may be due to CTAB (surfactant). The toxicity of CTAB was investigated by Wang et al. (2008) and Alkilany et al. (2009). Similar toxic effects of nanoparticles on HEP-2 and MDCK cells were reported by Zhang et al., (2012). This difference in toxicity cannot be explained only by the size and shape of the nanoparticle. To account for the difference, two interesting explanations have been proposed. One of them involves the charge on the nanoparticle while the other pertains to the diffusion pathway. In the case of the former, it has been shown that gold nanoparticles which are cationic are more toxic as it is easier for them to be absorbed into the negatively charged cell membrane; in the case of the latter, nanoparticles that are cationic can pass through the cell membrane via the direct diffusion pathway while anionic nanoparticles have to pass through the cell membrane by endocytosis. Given that both GNRs and PAH/PSS-GNRs are cationic while GNSs and PSS-GNRs are anionic, these characteristics in combination with the toxic surfactant (CTAB) may explain the greater toxicity exhibited by GNRs. 
Nanoparticles can induce oxidative stress in human fibroblasts, erythrocytes, vascular endothelial cells, mesenchymal stem cells and a variety of tumour cells (Abdal Dyem et al., 2017). Nanoparticles have also been shown to cause oxidative stress in zebrafish embryos and in the liver of adult zebrafish (Choi et al., 2010; Du et al., 2017; Faria et al., 2014; Zhao et al., 2016). Catalase, GPX and SOD are detoxifying enzymes for ROS that regulate redox homeostasis (Abdal Dyem et al., 2017). Bcl2 plays an important role in regulation of ROS generation and maintenance of the redox status (Hockenbery et al., 1993). Du et al. (2017) showed that zinc oxide nanoparticle treatment resulted in significant increases in SOD and GPX activities in zebrafish embryos. Zhao et al. (2016) also demonstrated significantly increased SOD activity in zebrafish embryos treated with zinc oxide nanoparticles. We found that GNRs markedly upregulated expression of Catalase, GPX1a, Sod1 and Bcl-2 genes (Fig. 6), suggesting that GNR treatment caused oxidative stress and led to antioxidant responses. adult zebrafish (Choi et al., 2010; Du et al., 2017; Zhao et al., 2016). We examined the apoptotic effects of nanoparticle exposure $(0.05 \mathrm{nM})$ and found the most common feature being the crowded bright spots in the heart and eye areas (Fig. 7), representing the accumulation of toxic substances ultimately leading to apoptosis. Bcl-2 is considered to be an anti-apoptotic protein that protects cells from apoptosis (Hockenbery et al., 1993). The high level of apoptosis observed in GNR-treated embryos (Fig. 7) was accompanied by a significant upregulation of Bcl-2 expression in GNR-treated embryos when compared to untreated control embryos (Fig. 6D), indicating a defensive response to counteract the damaging effects of GNR exposure. A previous study reported that myocyte apoptosis can lead to dilated cardiomyopathy (Wencker et al., 2003). Similar results were reported when zebrafish were treated with hexabromocyclododecane (HBCD) and microcystins (MCs). 
treatment process, which may result in a reduction of heart rate and blood flow and ultimately slowing growth and development (Zeng et al., 2014; Ulukaya et al., 2011; Deng et al., 2009). Similar results were reported by Zhang et al., 2012, when nanoparticles were tested on HEP2 and MDCK cells. Abnormalities were also observed in the higher concentration of each sample. The abnormalities include slimy fluid with brown flakes, abnormal spine, heart oedema, curved tail, and degraded body parts (data not shown).

\section{CONCLUSION}

GNRS and PSS-GNRS exhibited significant toxic action by increasing mortality and by decreasing hatching and heart rate. The results clearly demonstrate that the GNRs are the most toxic and GNSs the least toxic of all the compared nanoparticles. PSS coating on GNRs nanoparticles reduced toxicity possibly by forming a protective layer around CTAB of GNRs. The addition of an extra layer of PAH on PSS-GNRs further reduced the toxicity. This may be a result of the coating which leads to the further isolation of toxic CTAB from cell membrane and hence a change in toxicity. This might suggest a new way to combat toxicity although further study is required.

\section{ACKNOWLEDGEMENT}

This work was supported by the Royal Society, the Rosetrees Trust (M160, M160-F1 and M160-F2), the Glasgow Children's Hospital Charity (YRSS/PSG/2014), and the Visual Research Trust (VR2014). Maintenance of the zebrafish facility was funded by the European Union INTERREG NEW noPILLS programme.

\section{REFERENCES}

Abdal Dayem, A., Hossain, M.K., Lee, S.B., Kim, K., Saha, S.K., Yang, G.M., ... Cho, S.G. (2017). The role of reactive oxygen species (ROS) in the biological activities of metallic nanoparticles. International Journal of Molecular Sciences, 18(1), pii: E120. 
347 Alkilany, A.M., Nagaria, P.K., Hexel, C.R., Shaw, T.J., Murphy, C.J., \& Wyatt, M.D (2009).

348 Cellular uptake and cytotoxicity of gold nanorods: molecular origin of cytotoxicity and 349 surface effects. Small, 5(6), 701-708.

350 Asharani, P.V., Low Kah Mun, G., Hande, M.P., \& Valiyaveettil, S. (2008).

351 Cytotoxicity and genotoxicity of silver nanoparticles in human cells. ACS Nano, 3(2), 279352290.

353 Asharani, P.V., Wu, Y.L., Gong, Z., \& Valiyaveettil, S. (2008). Toxicity of silver 354 nanoparticles in zebrafish models. Nanotechnology, 19(25), 255102.

355 Bar-Ilan, O., Albrecht, R. M., Fako, V. E., \& Furgeson, D. Y. (2009).

356 Toxicity assessments of multisized gold and silver nanoparticles in zebrafish embryos.

357 Small, 5(16), 1897-1910.

358 Cattaneo, A. G., Gornati, R., Bernardini, G., Sabbioni, E., Manzo, L., \& Di Gioacchino, M. 359 (2014). Testing nanotoxicity: an update of new and traditional methods. Handbook of 360 Nanotoxicology, Nanomedicine and Stem Cell Use in Toxicology, 3-34.

361 Choi, J.E., Kim, S., Ahn, J.H., Youn, P., Kang, J.S., Park, K., ... Ryu, D.Y. (2010).

362 Induction of oxidative stress and apoptosis by silver nanoparticles in the liver of adult 363 zebrafish. Aquatic Toxicology, 100, 151-159.

364 Deng, J., Yu, L., Liu, C., Yu, K., Shi, X., Yeung, L.W., ... Zhou, B. (2009).

365 Hexabromocyclododecane-induced developmental toxicity and apoptosis in zebrafish 366 embryos. Aquatic Toxicology, 93(1), 29-36.

367 Du, J., Cai, J., Wang, S., \& You, H. (2017). Oxidative stress and apotosis to zebrafish (Danio 368 rerio) embryos exposed to perfluorooctane sulfonate (PFOS) and $\mathrm{ZnO}$ nanoparticles. International Journal of Occupational Medicine and Environmental Health, 30(2), 213-229. 

effects of titanium dioxide nanoparticle aggregates in zebrafish embryos. Science of the Total Environment, 470-471, 379-389. Gu, A.H., Shi, X.G., Yuan, C., Ji, G.C., Zhou, Y., Long, Y., ... Wang, X.R. (2010). Exposure to fenvalerate causes brain impairment during zebrafish development. Toxicology Letters, 197, 188-192.

Hanley, C., Thurber, A., Hanna, C., Punnoose, A., Zhang, J., \& Wingett, D.G. (2009). The influences of cell type and $\mathrm{ZnO}$ nanoparticle size on immune cell cytotoxicity and cytokine induction. Nanoscale research letters, 4(12), 1409.

Hockenbery, D.M., Oltvai, Z.N., Yin, X.M., Milliman, C.L., Korsmeyer, S.J. (1993). Bcl-2 functions in an antioxidant pathway to prevent apoptosis. Cell, 75(2), 241-251. Jiang, J.Q., Zhou, Z., Patibandla, S., \& Shu, X. (2013). Pharmaceutical removal from wastewater by ferrate (VI) and preliminary effluent toxicity assessments by the zebrafish embryo model. Microchemical Journal, 110, 239-245.

Kimling, J., Maier, M., Okenve, B., Kotaidis, V. Ballot, H., \& Plech, A. (2006). Turkevich method for gold nanoparticle synthesis revisited. Journal of Physical Chemistry B, 109, 15700-15707.

Marambio-Jones, C., \& Hoek, E. M. V. (2010). A review of the antibacterial effects of silver nanomaterials and potential implications for human health and the environment. Journal of Nanoparticle Research, 12(5), 1531- 1551.

Murphy, C.J. \& Jana, N.R. (2002). Controlling the aspect ratio of inorganic nanorods and nanowires. Advanced Materials, 14(1), 80-82. polymer- and silica-coated gold nanorods. Analytical Sciences, 25(2), 255-259. 
Salata, O. V. (2004) Applications of nanoparticles in biology and medicine. Journal of Nanobiotechnology, 2(1), 3.

Shu, X., Zeng, Z., Gautier, P., Lennon, A., Gakovic, M., Patton, E.E., \& Wright, A.F. (2010).

Zebrafish Rpgr is required for normal retinal development and plays a role in dynein-based retrograde transport processes. Human Molecular Genetics, 19(4), 657-670.

Si, J., Zhang, H., Wang, Z., Wu, Z., Lu, J., Di, C., ... Wang X. (2013). Effects of 12C 6+ ion radiation and ferulic acid on the zebrafish (Danio rerio) embryonic oxidative stress response and gene expression. Mutation Research, 745-746, 26-33.

Ulukaya, E., Acilan, C., \& Yilmaz, Y. (2011). Apoptosis: why and how does it occur in biology? Cell Biochemistry and Function, 29(6), 468-480.

Wencker, D., Chandra, M., Nguyen, K., Miao, W., Garantziotis, S., Factor, S.M., \& Kitsis, R.N. (2003). A mechanistic role for cardiac myocyte apoptosis in heart failure. Journal of Clinical Investigation, 111(10), 1497-1504. Wang, S., Lu, W., Tovmachenko, O., Rai, U.S., Yu, H., \& Ray, P.C. (2008). Challenge in understanding size and shape dependent toxicity of gold nanomaterials in human skin keratinocytes. Chemical Physics Letters, 463(1), 145-149.

413 Wei, G., Simionesie, D., Sefcik, J., Sutter, J. U., Xue, Q., Yu, J., ... Chen, Y. (2015). 414 Revealing the photophysics of gold-Nanobeacons via time-resolved fluorescence spectroscopy. Optics Letters, 40, 5738-5741.

416 Wei, G., Yu, J., Wang, J., Gu, P., Birch, D.J.S., \& Chen, Y. (2016). Hairpin DNA417 functionalized gold nanorods for mRNA detection in homogenours solution. Journal 418 of Biomedical Optics, 21(9), 97001. 
419 Wolf, K., Stafoggia, M., Cesaroni, G., Andersen, Z.J., Beelen, R., Galassi, C., ... Forastiere, 420 F. (2015). Long-term Exposure to Particulate Matter Constituents and the Incidence of 421 Coronary Events in 11 European Cohorts. Epidemiology, 26(4), 565-574.

422 Zhang, Y., Yu, j., Birch, D. J., \& Chen, Y. (2010). Gold nanorods for fluorescence lifetime 423 imaging in biology. Journal of Biomedical Optics, 15, 20504.

424 Zhang, Y., Birch, D.J.S., \& Chen, Y. (2011). Two-photon excited surface plasmon enhanced 425 energy transfer between DAPI and gold nanoparticles: Opportunities in intra-cellular imaging 426 and sensing. Applied Physics Letters, 99, 103701.

427 Zhang, Y., Xu, D., Li, W., Yu, J., \& Chen, Y. (2012) Effect of size, shape, and surface 428 modification on cytotoxicity of gold nanoparticles to human HEp-2 and canine MDCK cells. 429 Journal of Nanomaterials, 2012, ID 375496.

430 Zhang, Y., Wei, G., Yu, J., Birch, D. J. S., \& Chen Y. (2015). Surface plasmon enhanced 431 energy transfer between gold nanorods and fluorophores: application to endocytosis study 432 and RNA detection. Faraday Discuss, 178, 383-394

433 Zeng, C., Sun, H., Xie, P., Wang, J., Zhang, G., Chen, N., ... Li, G. (2014). The role of 434 apoptosis in MCLR-induced developmental toxicity in zebrafish embryos. Aquatic 435 Toxicology, 149, 25-32.

436 Zhao, X., Ren, X., Zhu, R., Luo, Z., \& Ren, B. (2016). Zinc oxide nanoparticles induce 437 oxidative DNA damage and ROS-triggered mitochondria-mediated apoptosis 438 in zebrafish embryos. Aquatic Toxicology, 180, 56-70. 
Table 1: Primers used in qRT-PCR.

\begin{tabular}{|c|l|l|}
\hline Gene name & \multicolumn{1}{|c|}{ Primer sequence } & Reference \\
\hline Gpx1a & $\begin{array}{l}\text { Forward: ACCTGTCCGCGAAACTATTG } \\
\text { Reverse: TGACTGTTGTGCCTCAAAGC }\end{array}$ & Choi JE et al., 2010 \\
\hline Catalase & $\begin{array}{l}\text { Forward: AGGGCAACTGGGATCTTACA } \\
\text { Reverse: TTTATGGGACCAGACCTTGG }\end{array}$ & Choi JE et al., 2010 \\
\hline Sod1 & $\begin{array}{l}\text { Forward: GTCGTCTGGCTTGTGGAGTG } \\
\text { Reverse : TGTCAGCGGGCTAGTGCTT }\end{array}$ & Si J et al., 2013 \\
\hline Bcl-2 & $\begin{array}{l}\text { Forward: AGGAAAATGGAGGTTGGGATG } \\
\text { Reverse : TGTTAGGTATGAAAACGGGTGG }\end{array}$ & Raghupathy R et al., 2015 \\
\hline 18 R RNA & $\begin{array}{l}\text { Forward : CCACTCCCGAGATCAACTA } \\
\text { Reverse : CAAATTACCCATTCCCGACA }\end{array}$ \\
\hline
\end{tabular}

441

442

443

444

445

446

447

448

449

450

451

452

453

454

455

456

457

458 


\section{Figure legends:}

Figure 1 Absorption spectra for GNRs, PSS-GNRs and GNSs

Figure 2 Transmission electric microscopy (TEM) images of gold nanospheres (A) and gold nanorods (B).

Figure 3 Mortality of zebrafish embryos following 120 hpf treatments with different concentrations of different nanoparticles. Eight embryos were used for each treatment. Significant increases in mortality rate relative to that of control fish were observed following exposure to all concentrations of GNRs and to 0.05 and $0.1 \mathrm{nM}$ PSS-GNRs. $\left({ }^{* * *} p<0.001\right.$; ** $\left.p<0.01 ;{ }^{*} p<0.05\right)$. Values are expressed as mean \pm standard deviation.

Figure 4 Hatching rate of zebrafish embryos following 72 hpf treatments with different concentrations of different nanoparticles. Eight embryos were used for each treatment. Significant decreases in hatching rate relative to that of control fish were observed following exposure to all concentrations of GNRs and PSS-GNRs and to 0.05 and $0.1 \mathrm{nM}$ PSS/PSHGNRs $\left({ }^{* * * *} p<0.0001 ;{ }^{* * *} p<0.001 ;{ }^{* *} p<0.01 ;{ }^{*} p<0.05\right)$. Values are expressed as mean \pm standard deviation.

Figure 5 Heart rate (beats per minute) of zebrafish embryos following 120 hpf treatments with different concentrations of different nanoparticles. Significant differences in heart rate relative to that of control fish were observed following exposure to 0.05 and $0.1 \mathrm{nM}$ GNRs and to $0.1 \mathrm{nM}$ PSS-GNRs $\left(* * * * p<0.0001 ;{ }^{* * *} p<0.001 ;{ }^{*} p<0.05\right)$. Values are expressed as mean \pm standard deviation.

Figure 6 Expression of oxidative stress genes in zebrafish embryos treated with nanoparticles (2.5 $\mu$ M GNS, $0.01 \mathrm{nM}$ GNR, $0.025 \mathrm{nM}$ PSS-GNR and $0.05 \mathrm{nM}$ PAH/PSS-GNR) from 6 hpf to 72 hpf. (A) Catalase, (B) Gpx1a, (C) Sod1, (D) Bcl-2. Significant differences in gene expression relative to that in control fish are indicated by asterisks $\left(* * * p<0.001\right.$ and $\left.{ }^{* *} p<0.01\right)$. Data were presented as mean \pm standard deviation.

Figure 7 Acridine orange staining of zebrafish embryos (48 hpf) treated with $0.05 \mathrm{nM}$ concentration of nanoparticles. (A) GNRs, (B) GNSs, (C) PSS-GNRs, (D) PSS/PSH-GNRs, (E) Control. (F)The bright green spots indicate the presence of apoptotic cells. The fluorescent signals were quantified using ImageJ, the relative fluorescent signals in treated zebrafish embryos were significantly higher than that of control embryos. GNRs-treated embryos had highest fluorescent signals. ${ }^{* * * *} \mathrm{p}<0.0001$. 
Figure 1

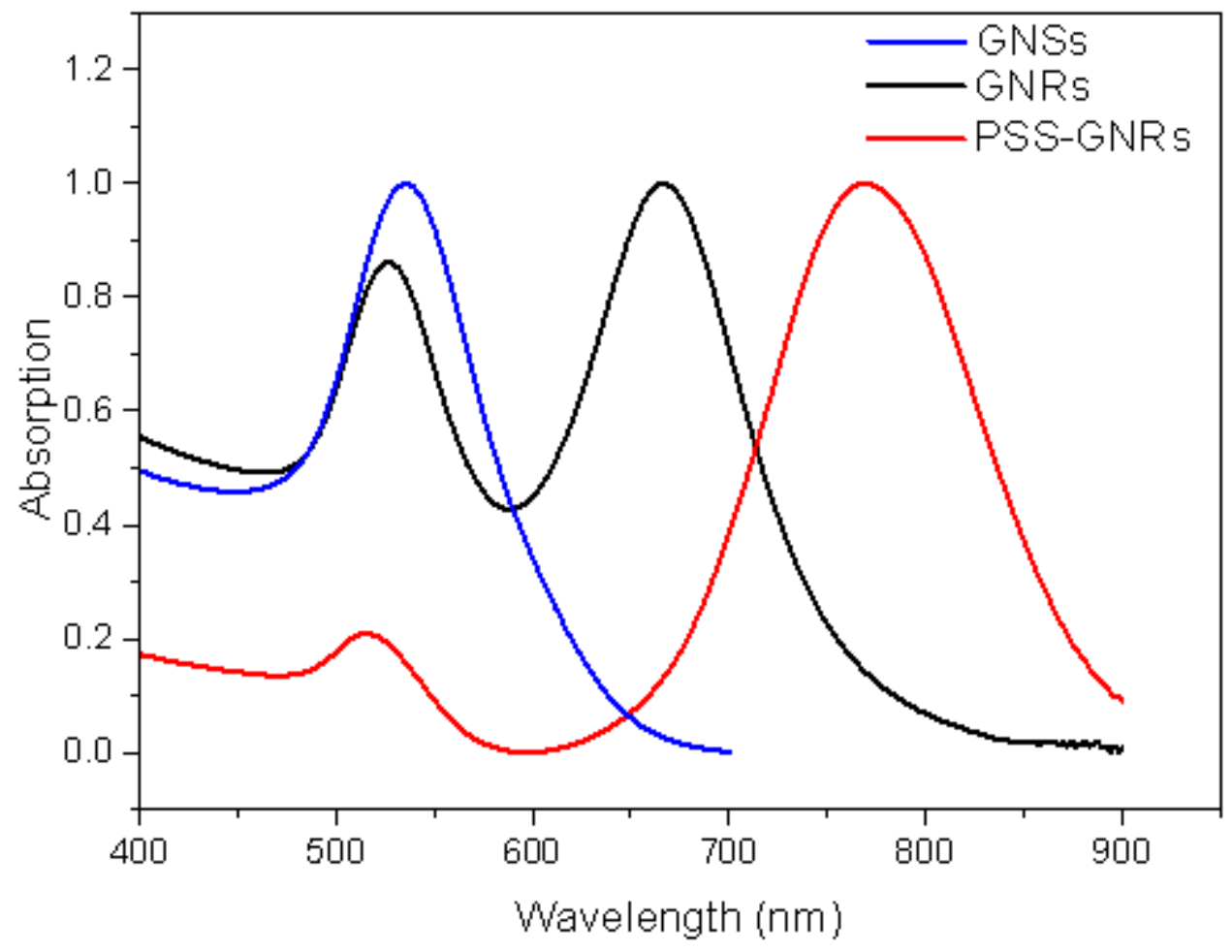

496

497

498

Figure 2
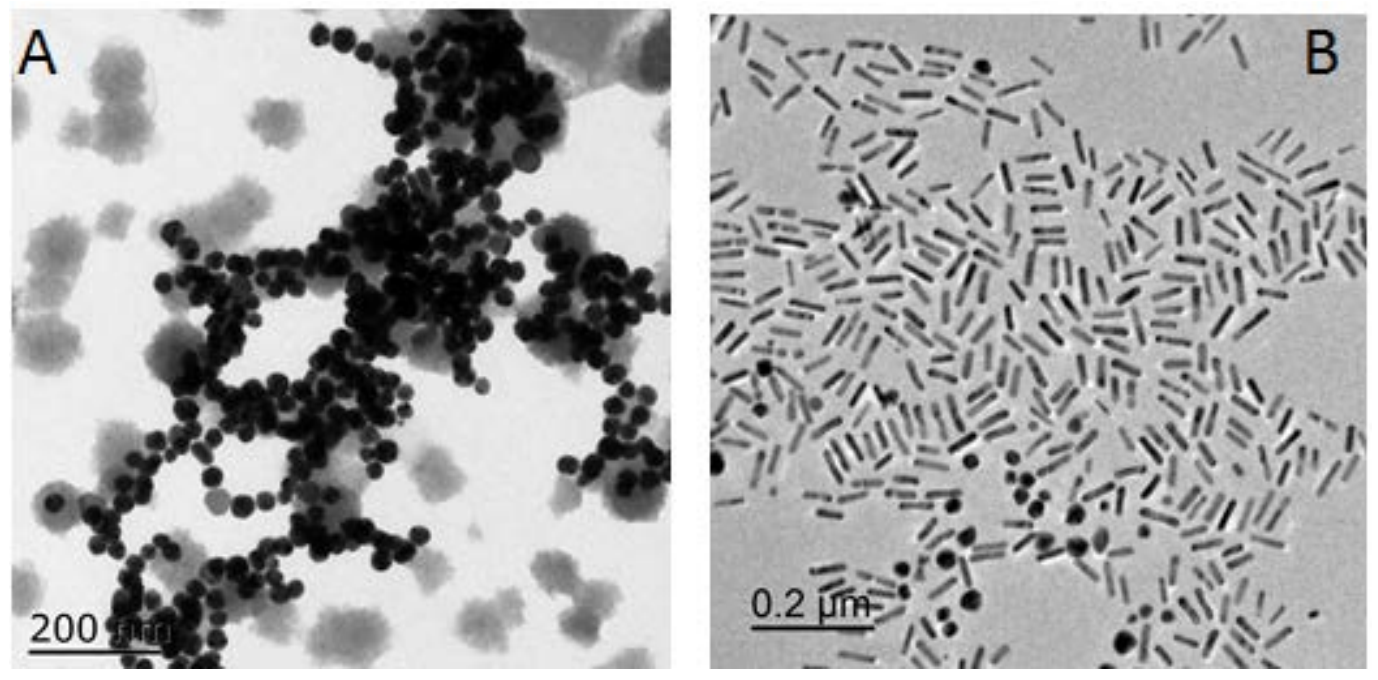

500

501

502

503 
Figure 3

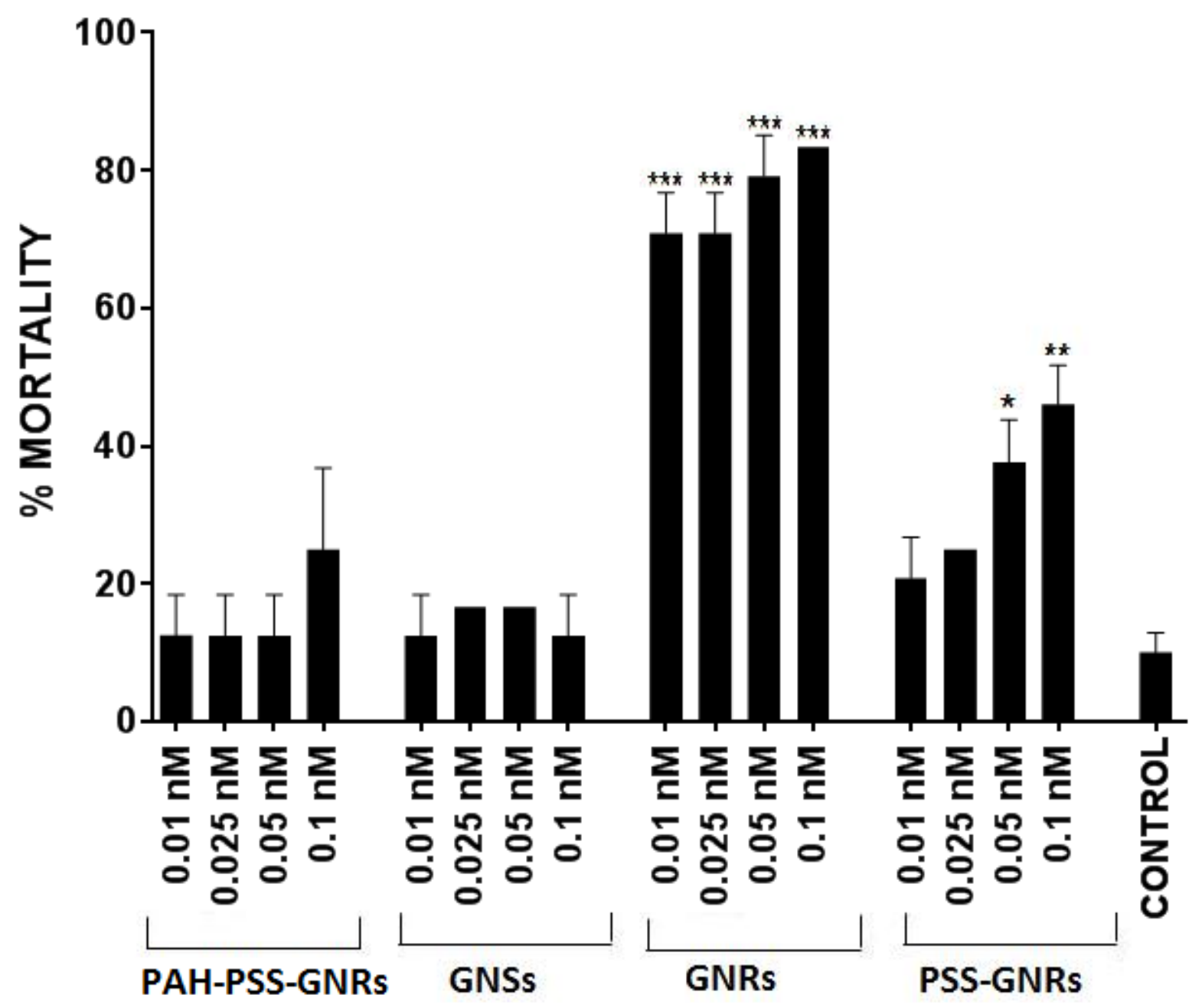


Figure 4

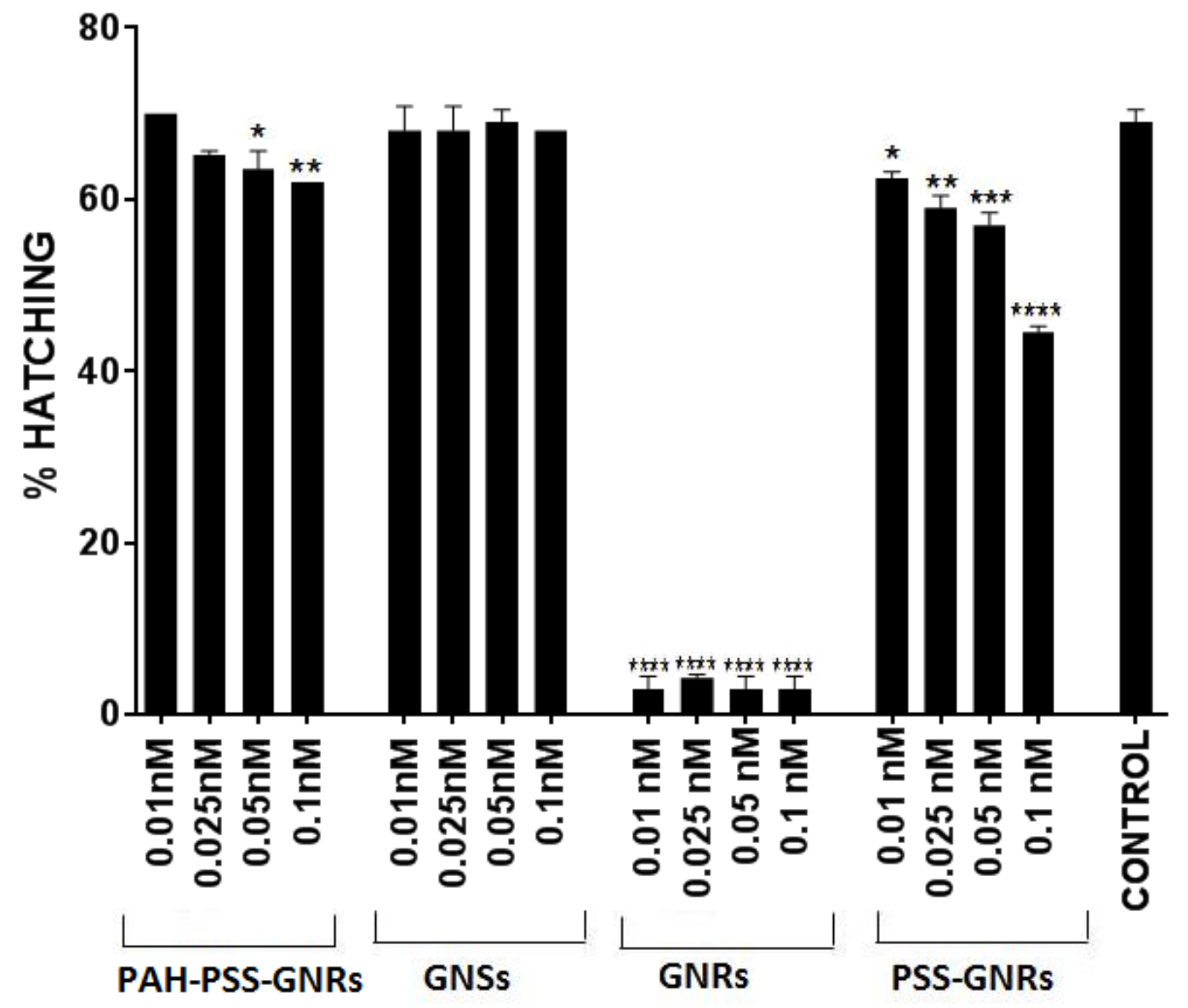

517 
Figure 5

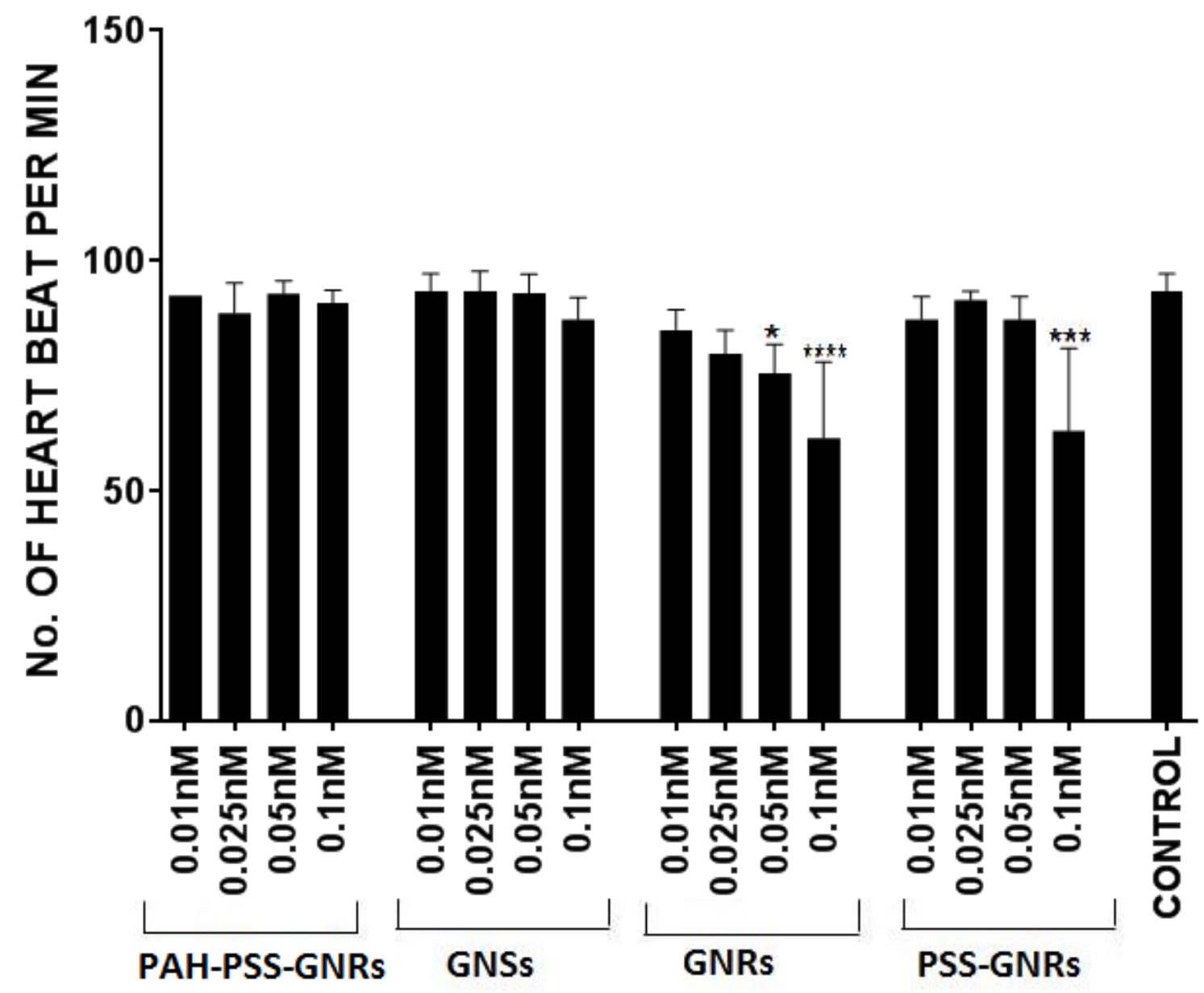


$544 \quad$ Figure 6
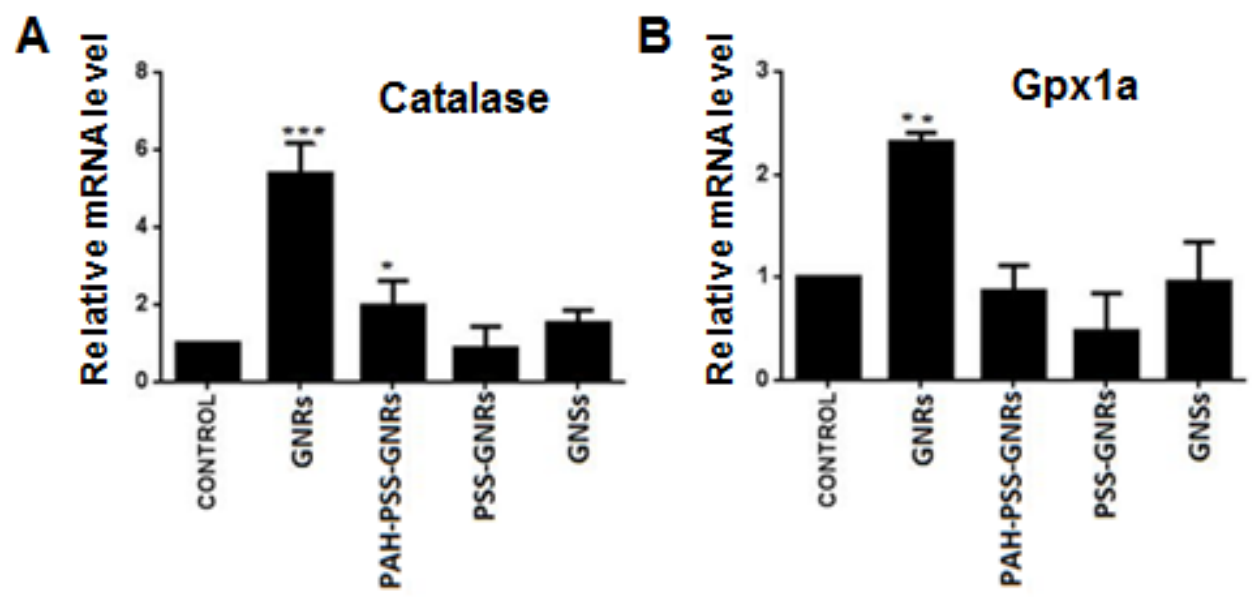

545
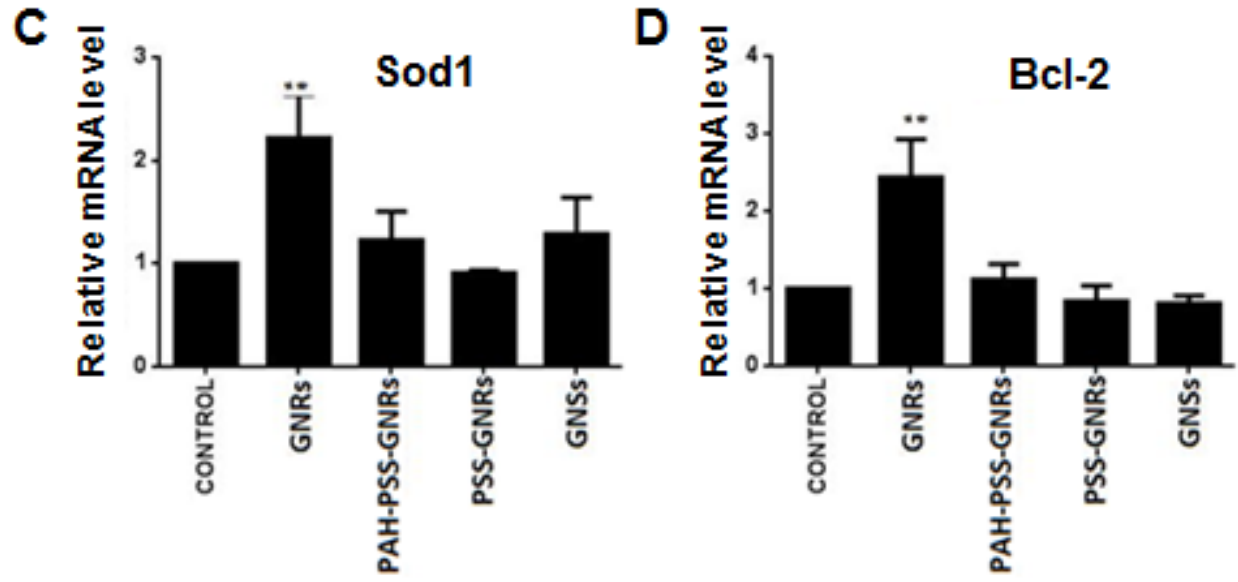

546

547

548

549

550

551

552

553

554

555

556

557

558 
$559 \quad$ Figure 7
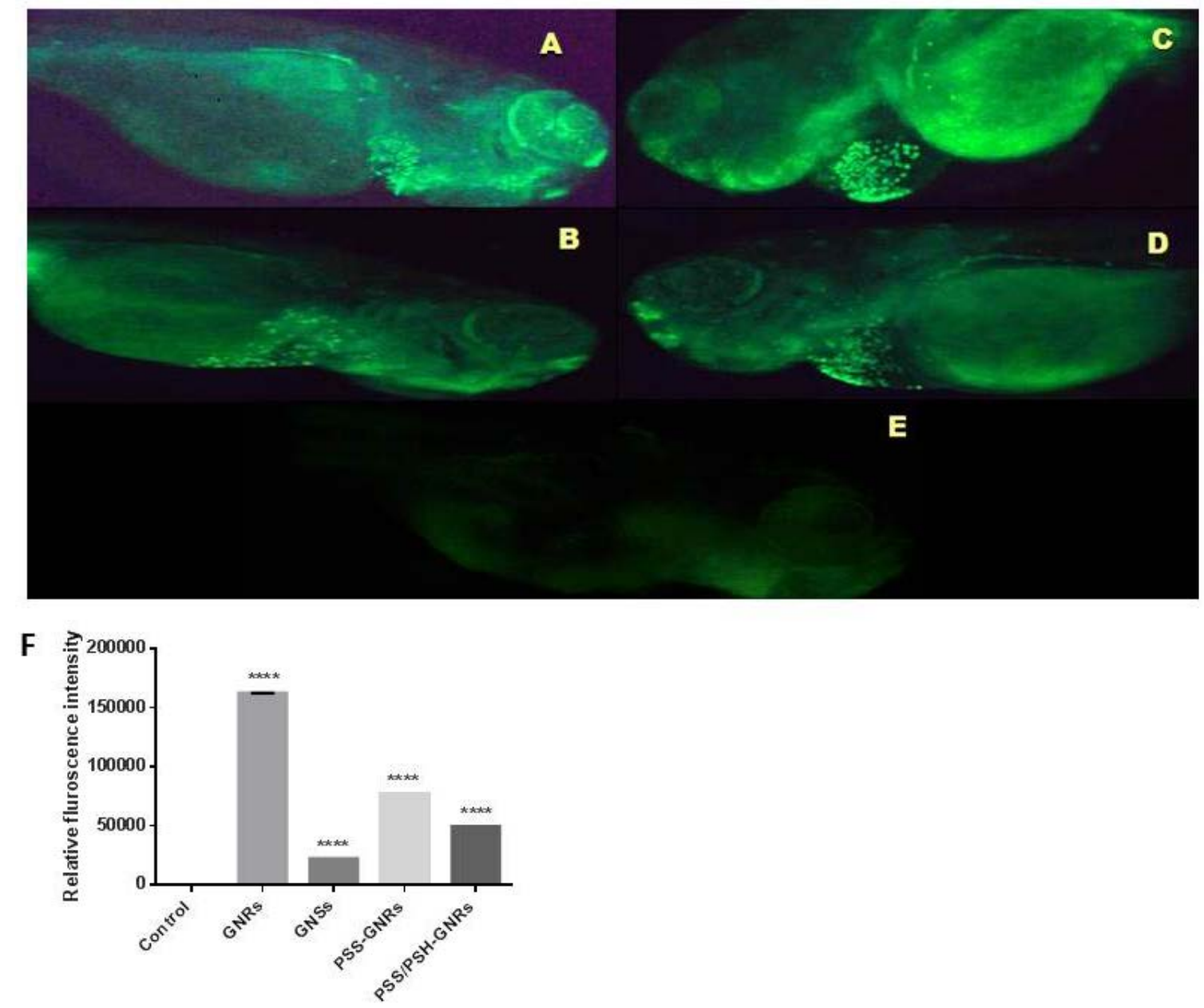

560

561 